\title{
Design of cationic nanostructured heterolipid matrices for ocular delivery of methazolamide
}

\author{
This article was published in the following Dove Press journal: \\ International Journal of Nanomedicine \\ 15 May 2012 \\ Number of times this article has been viewed
}

\author{
John Youshia \\ Amany O Kamel \\ Abdelhameed El Shamy \\ Samar Mansour \\ Pharmaceutics and Industrial \\ Pharmacy Department, Faculty \\ of Pharmacy, Ain Shams University, \\ Cairo, Egypt
}

Correspondence: Amany Kamel; Samar Mansour

African Union Organization St, Abbaseya, POB II 1566, Egypt

Tel +20 $200 \mid 4292 I$

$\mathrm{Fax}+2022405$ II 06; +202 2405।I107

Email amany.kamel@yahoo.com;

samar_holayel@yahoo.com

\begin{abstract}
Solid lipid nanoparticles (SLNs) formulated from one type of lipid (homolipid) suffer from low drug encapsulation and drug bursting due to crystallization of the lipid into the more ordered $\beta$ modification, which leads to decreased drug entrapment and faster drug release. This study assessed the feasibility of using nanostructured lipid matrices (NLMs) for ocular delivery of methazolamide-(MZA) adopting heterolipids composed of novel mixtures of Compritol $^{\circledR}$ and cetostearyl alcohol (CSA), and stabilized by Tween $80^{\circledR}$. The systems were prepared using the modified high shear homogenization followed by ultrasonication method, which avoids the use of organic solvents. A $3^{2}$ full factorial design was constructed to study the influence of two independent variables, namely the ratio of CSA:Compritol and the concentration of Tween 80 , each in three levels. The dependent variables were the entrapment efficiency percentages (EE\%), mean particle size (PS), polydispersity index (PDI), and zeta potential (ZP). In vivo intraocular pressure (IOP) lowering activity for the selected formulae was compared to that of MZA solution. The results showed that increasing the ratio of CSA to Compritol increased the EE\% and PS, while increasing the concentration of Tween 80, decreased PS with no significant effect on $\mathrm{EE} \%$. The ZP values of all formulae were positive, and greater than $30 \mathrm{mV}$. The best formula, composed of 4\% CSA, 2\% Compritol, $0.15 \%$ stearylamine, and $2 \%$ Tween 80 , with $\mathrm{EE} \%$ of $25.62 \%$, PS of $207.1 \mathrm{~nm}$, PDI of 0.243 , and $\mathrm{ZP}$ of $41.50 \mathrm{mV}$, showed in vitro sustained release properties for 8 hours and lowered the intraocular pressure by $8.3 \mathrm{mmHg}$ within 3 hours, with this drop in pressure lasting for 12 hours.
\end{abstract}

Keywords: nanostructured lipid matrices, heterolipids, factorial design, cetostearyl alcohol, methazolamide, ocular delivery

\section{Introduction}

Conventional ocular drug delivery systems such as eye drops suffer from very poor bioavailability because the eye is protected by complicated defense mechanisms that make it difficult to achieve an effective drug concentration in the target area. Colloidal drug delivery systems such as liposomes and emulsions have been developed to solve this problem, ${ }^{1,2}$ but they suffer from poor stability. Solid lipid nanoparticles (SLNs) are colloidal particles developed as an alternative to emulsions, liposomes, and polymeric nanoparticles for the delivery of hydrophilic, lipophilic, and/or poorly water soluble drugs. They have a number of advantages including the use of biodegradable, biocompatible, and physiological lipids, the avoidance of organic solvents during preparation, high bioavailability, and the possibility of large-scale production and sterilization. ${ }^{3-5}$ The solid matrix of SLNs tightly binds the drug molecules and so releases incorporated drugs more slowly than conventional fluid colloidal lipid drug 
carriers, while also improving the stability of drugs against decomposition. SLNs enhance ocular drug delivery by facilitating corneal penetration due to their lipophilic character, ${ }^{6}$ and ensure adherence to ocular membranes, while their small size and particulate nature prevents tear wash out. ${ }^{7}$

However, SLNs formulated from a single type of lipid (homolipid) suffer from low drug encapsulation and possible drug bursting due to crystallization of the lipid into the more ordered $\beta$ modification, ${ }^{5}$ which shows a high degree of order and limited imperfections in the crystal lattice. ${ }^{8}$ The use of mixtures of lipids which do not form a highly ordered crystalline arrangement is needed to overcome these limitations. Such a lipid matrix could be achieved by using a combination of solid lipid and oil, which is termed a nanostructured lipid carrier, ${ }^{9}$ or through the use of a solid lipid mixture (heterolipids) with a complex nature that includes different chain lengths and melting points, which is called a nanostructured lipid matrix (NLM). ${ }^{10,11}$ Mixing lipids modifies the polymorphic properties of the single lipid, and has been proven to produce lipid matrices of low crystallinity. ${ }^{10}$

Compritol and cetostearyl alcohol (CSA) has not previously been studied for the preparation of NLMs. Compritol is generally regarded as safe (GRAS), and is a biocompatible, nonirritant, and nontoxic partial triglyceride of behenic acid $\left(\mathrm{C}_{21} \mathrm{H}_{43} \mathrm{COOH}\right)$. It is mainly composed of glyceryl dibehenate with variable quantities of glyceryl mono- and tribehenate. CSA is a mixture of solid aliphatic fatty alcohols consisting primarily of stearyl alcohol (1-octadecanol, $\mathrm{C}_{18} \mathrm{H}_{37} \mathrm{OH}$ ) and cetyl alcohol (1-hexadecanol, $\mathrm{C}_{16} \mathrm{H}_{33} \mathrm{OH}$ ). It is commonly used in cosmetics and topical preparations, and is generally regarded as nontoxic and nonirritant to the eyes. $^{12}$

Methazolamide (MZA) is a sulfonamide derivative that is weakly acidic, and slightly soluble in water. It is a systemically administered carbonic anhydrase inhibitor (CAI) used for the treatment of glaucoma, but it possesses some side effects such as numbness and tingling of extremities, a metallic taste, and metabolic acidosis due to the presence of carbonic anhydrase enzyme in many tissues and organs. Topical administration of MZA directly to the eye may reduce systemic side effects, but MZA's poor aqueous solubility $\left(1.7 \mathrm{mg} / \mathrm{mL} \text { at } 25^{\circ} \mathrm{C}\right)^{13}$ and low corneal permeability $\left(1.75 \times 10^{-4} \mathrm{~cm} / \text { hour }\right)^{14}$ make topical administration difficult. Previous attempts have been made to formulate topical MZA including MZA cyclodextrin eye drops, ${ }^{15} \mathrm{MZA}$ calcium phosphate nanoparticles, ${ }^{16} \mathrm{MZA}$ in situ gels, ${ }^{17}$ and MZA solid lipid nanoparticles by modified emulsion-solvent evaporation (which involved the use of organic solvents). ${ }^{18}$
MZA cyclodextrin eye drops increased aqueous solubility of MZA, however there still exists the possibility of tissue irritation and toxicological implications caused by the use of cyclodextrin as a penetration enhancer. ${ }^{19}$ Also, using SLNs composed of homolipid were not successful in sustaining drug release, with approximately $77 \%$ released in the first hour. ${ }^{18}$

The objective of this study was to assess the feasibility of using NLMs for ocular delivery of MZA-adopting heterolipids composed of novel mixtures of Compritol and CSA stabilized by Tween ${ }^{\circledR}$. The NLMs were prepared using the modified high shear homogenization followed by ultrasonication method, which avoids the use of organic solvents. ${ }^{20}$ The use of heterolipids was expected to create imperfections in the crystal lattice, providing more space that can localize more drug, and thus improving the entrapment efficiency. A $3^{2}$ full factorial design was built up to optimize the production process by studying the effect of using different CSA:Compritol ratios and various concentrations of Tween 80 on entrapment efficiency percentages (EE\%), mean particle size (PS), polydispersity index (PDI), and zeta potential (ZP). The intraocular pressure (IOP) lowering activity was evaluated in rabbits' eyes and compared to that of MZA solution.

\section{Materials and methods \\ Materials}

Methazolamide (MZA) was purchased from Jiaxing Taixing Chemical and Pharm Co, Ltd, (Jiaxing, China). Compritol $^{\circledR} 888$ ATO was kindly gifted by Gattefossé (Saint-Priest, France). Stearylamine (SA) was purchased from Sigma Chemical Co, Tween 80, cetostearyl alcohol (CSA), potassium dihydrogen phosphate, disodium hydrogen phosphate, and sodium chloride were purchased from Adwic, El-Nasr Pharmaceutical Co, (Cairo, Egypt). Spectra/Por dialysis membrane (12,000-14,000 molecular weight cut off) was purchased from Spectrum Laboratories Inc, (Rancho Dominguez, CA). Benoxinate hydrochloride eye drops $0.4 \%(\mathrm{w} / \mathrm{v})$ was purchased from Egyptian International Pharmaceutical Industries (EIPICO) (Cairo, Egypt).

\section{Design of the experiments}

A $3^{2}$ full factorial design was built up for optimization of the preparation of cationic MZA-loaded NLMs. The study design involved the investigation of the effect of two independent variables, namely lipid composition $\left(\mathrm{X}_{1}\right)$ and percentage of Tween $80\left(\mathrm{X}_{2}\right)$. Lipid composition was studied 
by changing the ratio of CSA to Compritol so that this was $2: 4,3: 3$, and $4: 2 \mathrm{wt} \%$; the percentage of Tween 80 was studied at $0.5,1$, and $2 \mathrm{wt} \%$. The dependent variables investigated were the entrapment efficiency percentages $\left(\mathrm{Y}_{1}\right)$, mean particle size $\left(\mathrm{Y}_{2}\right)$, polydispersity index $\left(\mathrm{Y}_{3}\right)$, and zeta potential $\left(\mathrm{Y}_{4}\right)$ of MZA-loaded NLMs. For comparative purposes, conventional SLNs were also prepared using Compritol. A typical design of the full factorial experiment is displayed in Table 1, and the composition of different formulae is shown in Table 2.

\section{Preparation of MZA-loaded NLMs}

Cationic MZA-loaded NLMs and SLNs were prepared by the modified high shear homogenization followed by ultrasonication method..$^{20}$ The total amount of the lipid phase in the developed formulations was kept constant at $6 \mathrm{wt} \%$. The lipid phase was composed of Compritol or Compritol together with CSA and $0.15 \mathrm{wt} \%$ stearylamine, and was heated to $80^{\circ} \mathrm{C}$ before $20 \mathrm{mg}$ MZA was dispersed in the molten lipids. An aqueous surfactant solution containing various concentrations of Tween 80 was heated to approximately the same temperature, and then poured into the hot lipid phase. Homogenization was carried out at 15,200 rpm for 5 minutes using a homogenizer (Ultra Turrax T25; IKA, Staufen, Germany). Both the lipid and the aqueous phases were heated to $80^{\circ} \mathrm{C}$ and stirred on magnetic stirrers (Yellow Line MAG HS 7, IKA). The obtained coarse hot oil in water emulsion was ultrasonicated for 30 minutes in a warmed bath sonicator at $40^{\circ} \mathrm{C}$ (Crest Ultrasonics, ETL testing laboratories, Cortland, NY), and SLNs and NLMs were obtained by allowing the hot nanoemulsion to cool to room temperature before being refrigerated at $4^{\circ} \mathrm{C}$. All of the above steps were done under aseptic conditions. All glassware were sterilized by autoclaving, and the entire procedure was carried out in a laminar flow hood (Esco, Singapore). All batches were prepared in triplicate.

\section{Determination of MZA entrapment efficiency}

The EE\% of MZA in SLNs and NLMs was determined by measuring the concentration of free drug in the nanoemulsion. The non-encapsulated MZA was separated by

Table I The factorial design independent variables and their levels

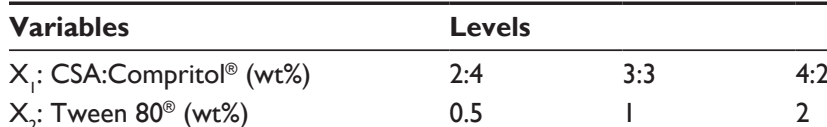

Abbreviation: CSA, cetostearyl alcohol. filtration/centrifugation using Nanosep ${ }^{\circledR}$ centrifuge tubes fitted with an ultra-filter (MWCO100KD; Pall Life Sciences, Port Washington, NY). A definite volume of the prepared NLM dispersion was diluted with distilled water, from which $500 \mu \mathrm{L}$ was transferred to the upper chamber of the Nanosep. The Nanosep was centrifuged at $9000 \mathrm{rpm}$ at $20^{\circ} \mathrm{C}$ for 2 hours (Z216 MK; Hermle, Gosheim, Germany). The amount of free drug in the filtrate was determined spectrophotometrically at 290 nm using a UV-visible spectrophotometer (model UV-1601 PC; Shimadzu, Kyoto, Japan). The UV-spectrophotometric analysis method was developed and validated in our laboratory. The EE\% was calculated as follows:

$$
\mathrm{EE} \%=\left(\frac{\mathrm{W}_{\mathrm{t}}-\mathrm{W}_{\mathrm{f}}}{\mathrm{W}_{\mathrm{t}}}\right) \times 100
$$

where $\mathrm{W}_{\mathrm{t}}$ is the total amount of drug used in the formulation and $\mathrm{W}_{\mathrm{f}}$ is the amount of free drug remaining in the supernatant.

\section{Particle size and zeta potential analysis}

The PS, PDI, and ZP of SLNs and NLMs were determined through dynamic light scattering (DLS, Zetasizer Nano ZS, Malvern instruments, Malvern, UK) at $25^{\circ} \mathrm{C}$ using disposable polystyrene cells and disposable plain folded capillary zeta cells. The samples were diluted with distilled filtered water before measurement. For PS analysis, a measurement angle of $173^{\circ}$ was used with the backscattering technique, while the ZP was calculated from the electrophoretic mobility using the Helmholtz-Smoluchowski equation. Measurements were performed in triplicate.

\section{Electron microscope examination}

The morphological observation of MZA-loaded NLMs was performed by transmission electron microscope (TEM) (JEM-1010; JEOL Ltd, Tokyo, Japan). One drop of the NLM suspension was deposited on a carbon-coated copper grid and then examined at 40 or $60 \mathrm{kV}$.

\section{In vitro release of MZA from NLMs}

In vitro drug release studies were performed using the dialysis membrane diffusion technique. The dialysis membrane of MWCO 12,000-14,000 (Spectra/Por) was used as this retained NLMs but allowed free drug into the release media. An accurately measured amount equivalent to $1 \mathrm{mg}$ MZA was transferred to a $2.5 \mathrm{~cm}$ diameter glass tube $10 \mathrm{~cm}$ in length that was open at both ends, with its lower end covered with the membrane presoaked in distilled water. ${ }^{21,22}$ The cylinder was fitted to the shaft and immersed 
Table 2 Composition of the prepared MZA-loaded NLM and SLN formulations, and their measured responses

\begin{tabular}{|c|c|c|c|c|c|c|}
\hline \multirow{2}{*}{$\begin{array}{l}\text { Formulation } \\
\text { code }\end{array}$} & \multicolumn{2}{|c|}{ Formulation composition $^{a}$} & \multicolumn{4}{|c|}{ Measured responses } \\
\hline & $\begin{array}{l}\text { CSA:Compritol } \\
\text { (wt\%) }\end{array}$ & $\begin{array}{l}\text { Tween } 80 \\
\text { (wt\%) }\end{array}$ & EE $(\%) \pm S E$ & $\begin{array}{l}\text { Mean size } \\
(\mathrm{nm}) \pm \mathrm{SE}\end{array}$ & PDI & $\begin{array}{l}\mathrm{ZP} \\
(\mathrm{mV}) \pm \mathrm{SE}\end{array}$ \\
\hline NLM-I & $2: 4$ & 0.5 & $14.57 \pm 1.12$ & $336.80 \pm 4.00$ & 0.218 & $53.25 \pm 1.02$ \\
\hline NLM-2 & $3: 3$ & 0.5 & $15.32 \pm 0.84$ & $416.50 \pm 4.82$ & 0.234 & $52.95 \pm 0.45$ \\
\hline NLM-3 & $4: 2$ & 0.5 & $27.97 \pm 0.16$ & $482.60 \pm 0.24$ & 0.267 & $52.65 \pm 0.20$ \\
\hline NLM-4 & $2: 4$ & I & $13.91 \pm 2.27$ & $317.85 \pm 1.18$ & 0.247 & $51.25 \pm 0.28$ \\
\hline NLM-5 & $3: 3$ & 1 & $22.24 \pm 0.72$ & $347.70 \pm 1.80$ & 0.275 & $49.85 \pm 0.04$ \\
\hline NLM-6 & $4: 2$ & I & $27.35 \pm 1.45$ & $391.70 \pm 4.65$ & 0.337 & $50.85 \pm 0.69$ \\
\hline NLM-7 & $2: 4$ & 2 & $16.91 \pm 0.63$ & $206.30 \pm 8.08$ & 0.230 & $42.45 \pm 0.12$ \\
\hline NLM-8 & $3: 3$ & 2 & $21.03 \pm 0.76$ & $196.20 \pm 7.19$ & 0.248 & $43.15 \pm 0.28$ \\
\hline NLM-9 & $4: 2$ & 2 & $25.62 \pm 0.89$ & $207.10 \pm 6.45$ & 0.243 & $41.50 \pm 0.33$ \\
\hline SLN-I & $0: 6$ & 2 & $11.29 \pm 0.58$ & $157.25 \pm 1.13$ & 0.240 & $38.30 \pm 0.00$ \\
\hline
\end{tabular}

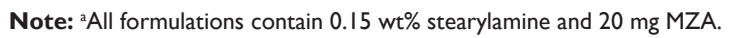

Abbreviations: CSA, cetostearyl alcohol; EE, entrapment efficiency; MZA, methazolamide; NLM, nanostructured lipid matrices; PDI, polydispersity index; SE, standard error of mean; SLN, solid lipid nanoparticles; ZP, zeta potential.

in the dissolution flask of the dissolution apparatus USP (Pharma Test, Hamburg, Germany) containing $50 \mathrm{~mL}$ phosphate-buffered saline (PBS) solution (pH 7.4). ${ }^{6}$ This volume provided complete sink conditions for the MZA. The entire system was kept at $37^{\circ} \mathrm{C} \pm 0.5^{\circ} \mathrm{C}$ with continuous stirring at $50 \mathrm{rpm}$. At different time intervals $(0.25,0.5$, $0.75,1,1.5,2,4,6$, and 8 hours), samples were withdrawn, replaced by fresh buffer, and assayed spectrophotometrically at $289 \mathrm{~nm}$. All the results presented are the mean values of three runs.

\section{Differential scanning calorimetry}

The thermal properties of pure MZA, a physical mixture composed of Compritol, CSA, MZA and stearylamine in same ratio of NLM-9 unloaded NLMs, and MZA-loaded NLMs formula NLM-9 were investigated using differential scanning calorimetry (DSC 60; Shimadzu). Samples (3-5 $\mathrm{mg}$ ) were sealed in aluminum pans with lids and heated at a rate of $10^{\circ} \mathrm{C} /$ minute to a temperature of $300^{\circ} \mathrm{C}$, using dry nitrogen as a carrier gas with a flow rate of $25 \mathrm{~mL} /$ minute. Indium was used as the standard reference material to calibrate the energy and scales temperature of the instrument.

\section{X-ray diffraction}

X-ray diffraction experiments were performed on pure MZA, Compritol, CSA, and the selected MZA NLM formula NLM-9 using an X-ray diffractometer (X-pert; Philips, Guildford, UK). The patterns of the samples were recorded with an area detector operating at $40 \mathrm{kV}$ and $30 \mathrm{~mA}$ using $\mathrm{CuKa}$ radiation $(\mathrm{k}=0.154 \mathrm{~nm})$ and $\mathrm{X}$-ray tube (PW3373/00CuLFF). X-ray diffractograms were obtained at a scanning rate of $1.2 \%$ minute and the scanning scope of $2 \theta$ was from 50 to 400 at room temperature.

\section{Effect of aging on PS}

The selected MZA NLM formulations were sealed in glass vials and stored in a refrigerator at $4^{\circ} \mathrm{C}$. Samples from each batch were withdrawn after storage for 1 month to study the effect of storage on PS of NLMs. The DLS technique (Zetasizer Nano ZS, Malvern Instruments) was used, as discussed above.

\section{In vivo study of cationic MZA-loaded NLMs}

Cationic MZA-loaded NLM formulations that showed high $\mathrm{EE} \%$ and suitable PS were selected to be tested for their intraocular pressure lowering effect on adult albino normotensive rabbits, and the results were compared to that of MZA solution. All preparations used in this study were adjusted to a concentration of $0.15 \% \mathrm{w} / \mathrm{v}$ MZA. Albino rabbits of average weight $2.5-3 \mathrm{~kg}$ were randomly divided into three groups, each consisting of three rabbits: Group I received MZA solution, Group II received formula NLM-6, and Group III received formula NLM-9. The rabbits were kept in individual cages with food and water, and were maintained in a 12-hour light/12-hour dark cycle in a temperature controlled room at $20^{\circ} \mathrm{C}-24^{\circ} \mathrm{C} .{ }^{23} \mathrm{~A}$ single $50 \mu \mathrm{L}$ dose of each preparation was administered at room temperature and instilled in the lower conjunctival sac corneal surface of the rabbit's left eye. The IOP was measured as a function of time using a standardized tonometer (Shiotz, Riester, Germany), ${ }^{24}$ by the same operator after instilling one drop of $0.4 \%(\mathrm{w} / \mathrm{v})$ benoxinate hydrochloride to the eye as a local anesthetic. IOP was first measured immediately before drug administration, then at 1, 2, 3, 4, 5, $6,7,8,10$, and 12 hours. In all the experimental rabbits, the right eye was left as a control. The ocular hypotensive activity was expressed as the average difference in IOP between the 
treated eye and the control eye to decrease the diurnal, seasonal, and individual variations usually observed in rabbits. ${ }^{23}$ The experimental procedures were performed according to ethical principles on the use of animals. ${ }^{24}$ The protocol of the study was approved by the ethical committee of the Egyptian Research Institute of Ophthalmology, Giza (Egypt).

\section{Data analysis}

Data were compared using a one-way analysis of variance (ANOVA) followed by Tukey-Kramer multiple comparisons test or Student's $t$-test using a demonstration version of GraphPad InStat 3 software (GraphPad Software, La Jolla, CA). The factorial experiment design and analysis was performed using $\operatorname{Minitab}^{\circledR}$ (v 15.1; Minitab Inc, State College, PA).

\section{Results and discussion}

The UV spectrophotometric analysis method used for the in vitro assay of MZA was developed and validated in our laboratory and was found to be linear over the range of 5-20 $\mu \mathrm{g} / \mathrm{mL}$, while the limit of detection and limit of quantification were found to be $0.125 \mu \mathrm{g} / \mathrm{mL}$ and $0.379 \mu \mathrm{g} / \mathrm{mL}$, respectively. The regression equation was $y=0.0459 x-$ 0.00398 where $y$ is the absorbance and $x$ is the concentration of MZA in $\mu \mathrm{g} / \mathrm{mL}(r=0.9993)$.

MZA-loaded NLMs were successfully prepared through the use of the modified high shear homogenization followed by ultrasonication method, which has the advantage of avoiding toxic organic solvents. Heterolipid mixtures of Compritol and CSA were used to increase the $\mathrm{EE} \%$ of $\mathrm{MZA}$ in the prepared formulations.

Preliminary studies (data not shown) were carried out to determine the factors to be included in the factorial design. CSA was compared to the results obtained from cetyl alcohol and Gelucire ${ }^{\circledR} 44 / 14$ (Gattefossé, Saint-Priest, France) and was found to be the most appropriate fatty alcohol to be mixed with Compritol. Different amounts of MZA were tested for entrapment into the prepared formulations, with $20 \mathrm{mg}$ found to be the most effective; this amount was used in all the prepared formulations.

Tween 80 was the surfactant of choice because of its non-ionic character and excellent ocular tolerability as it is reported to be non-irritating to the rabbits' eyes up to a concentration of $10 \% .{ }^{25}$ Stearylamine (SA) has been commonly used in preparing cationic emulsions intended for ocular drug delivery and was found to be non-irritating, with no evidence of inflammatory or toxic response when instilled in rabbits' eyes. ${ }^{26} \mathrm{SA}$ was chosen to serve multiple roles. The first of these was to impart a positive charge to produce cationic NLMs that could elicit electrostatic adhesion or interaction with the negatively charged mucin of the corneal epithelium, hence increasing ocular contact time and providing prolonged release. ${ }^{22}$ The second role was to enhance EE\%, as MZA is a weak acid and will undergo electrostatic interaction with the positively charged SA. This increase in EE\% was confirmed in our preliminary studies. Finally, SA also acts as a co-surfactant for further PS reduction.

\section{Effect of variables on optimized MZA NLMs EE\% response}

Table 2 shows that the EE\% of the prepared NLM formulations were in the range of $13.91 \%$ to $27.97 \%$, which were higher than that of the SLN formula (SLN-1) containing Compritol only which gave the lowest EE\% of value $11.29 \%$. This confirms that using heterolipids gave a better EE\% than a homolipid. This may be due to the fact that mixtures of lipids created defects in the crystal lattice, providing more room for the entrapment of MZA into the prepared NLM formulations. ${ }^{27}$ Table 3 shows that only CSA:Compritol ratio had a significant effect on MZA entrapment into NLMs $(P<0.001)$ while Tween 80 concentration had no significant effect.

Table 3 ANOVA analysis for dependent variables (EE\% and PS)

\begin{tabular}{|c|c|c|c|c|c|c|c|}
\hline \multirow{2}{*}{$\begin{array}{l}\text { Source of } \\
\text { variation }\end{array}$} & \multirow[t]{2}{*}{ DF } & \multicolumn{3}{|l|}{ EE (\%) } & \multicolumn{3}{|l|}{ PS (nm) } \\
\hline & & $\begin{array}{l}\text { Sum of } \\
\text { squares }\end{array}$ & $\begin{array}{l}\text { Mean } \\
\text { square }\end{array}$ & $F$ value & $\begin{array}{l}\text { Sum of } \\
\text { squares }\end{array}$ & $\begin{array}{l}\text { Mean } \\
\text { square }\end{array}$ & $F$ value \\
\hline CSA:Compritol & 2 & 646.302 & 323.151 & $158.89^{s}$ & 24376 & 12188 & $307.05^{s}$ \\
\hline Tween 80 & 2 & 21.473 & 10.736 & 5.28 & 208222 & I04III & $2622.86^{s}$ \\
\hline CSA:Compritol & 4 & 84.211 & 21.053 & $10.35^{s}$ & 16108 & 4027 & $101.45^{s}$ \\
\hline \multicolumn{8}{|l|}{ Tween 80} \\
\hline Error & 17 & 34.574 & 2.034 & - & 675 & 40 & - \\
\hline Total & 26 & 786.561 & - & - & 249380 & - & - \\
\hline
\end{tabular}

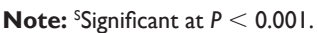

Abbreviations: ANOVA, analysis of variance; CSA, cetostearyl alcohol; DF, degrees of freedom; EE, entrapment efficiency; PS, particle size. 
Figure 1A shows that increasing CSA concentration from 2 to $4 \mathrm{wt} \%$ significantly increased the mean $\mathrm{EE} \%$ values of MZA in the prepared formulations from $15.13 \%$ to $26.98 \%$ $(P<0.001)$. This could be explained by CSA being a mixture of solid aliphatic alcohols consisting mainly of stearyl alcohol and cetyl alcohol - both have an alcohol group while Compritol is mainly composed of glyceryl dibehenate, which is an ester of behenic acid. The presence of the alcohol group and its lower number of carbon atoms means that CSA is relatively less hydrophobic than Compritol. MZA is a relatively hydrophilic drug with $\log \mathrm{p}=-0.2$, so CSA provided a good medium for its entrapment, and this entrapment increases with increasing CSA ratio. This agrees with previous results where fatty alcohols were found to be capable of creating a less ordered solid lipid matrix, leaving space for the accommodation of drug molecules. ${ }^{28}$ Moreover, fatty alcohols such as cetyl alcohol were reported to successfully entrap hydrophilic drugs such as buspirone $\mathrm{HCl}^{29}$ and Pentoxyfilline. ${ }^{30}$

Figure $1 \mathrm{~B}$ and Table 3 show that there was a significant two way interaction between the lipid composition and Tween 80 concentration. The prepared formulations with 4:2 (CSA:Compritol) wt\% ratio (NLM-3, NLM-6, and NLM-9) gave the highest $\mathrm{EE} \%$ at all levels of Tween 80 , followed by 3:3 (NLM-2, NLM-5, and NLM-8) and 2:4 (NLM-1, NLM-4, and NLM-7) wt\% ratios, respectively, as previously discussed. It was also found that increasing the ratio of CSA:Compritol from $2: 4$ to $3: 3 \mathrm{wt} \%$ the ratio at $0.5 \mathrm{wt} \%$ Tween 80 (Formula NLM-2) did not result in a significant increase in the EE\% when compared to formula NLM-1.

\section{Particle size and polydispersity index response}

The results of PS and PDI of the freshly prepared MZA formulations are presented in Table 2. All NLM formulations

A

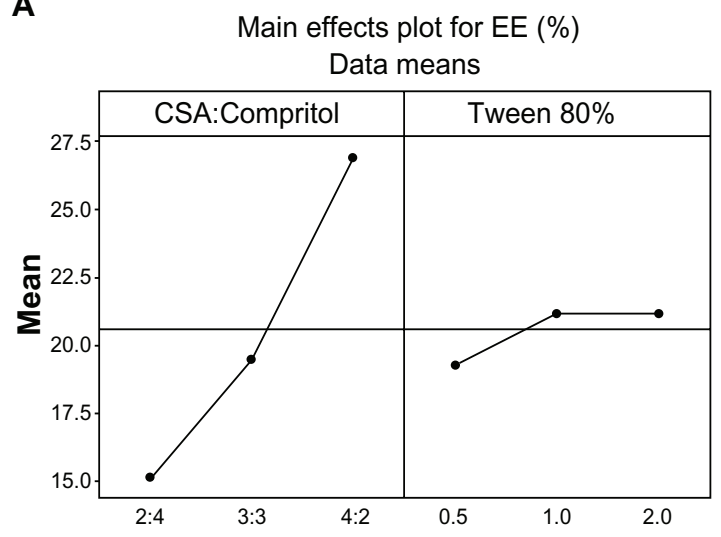

showed a mean PS below $500 \mathrm{~nm}$, and ranged from $196.2 \mathrm{~nm}$ to $482.6 \mathrm{~nm}$. This is an excellent size for ocular delivery as the human eye can tolerate particles as large as $10 \mu \mathrm{m} .{ }^{31}$ PDI values ranged from 0.218 to 0.337 . Tables 3 and 4 show that both the CSA:Compritol ratio and Tween 80 concentration had significant effects on MZA-loaded NLM particle size and PDI $(P<0.001)$. Furthermore, a significant two-way interaction $(P<0.001)$ was observed between lipid composition and Tween 80 concentration on PS and PDI, which indicates that both PS and PDI are dependent on these factors.

Figure $2 \mathrm{~A}$ shows that increasing CSA concentration from 2 to $4 \mathrm{wt} \%$ significantly increased the PS from $286.9 \mathrm{~nm}$ to $360.4 \mathrm{~nm}(P<0.001)$, while increasing Tween 80 concentration from 0.5 to $2 \mathrm{wt} \%$ caused PS to drop from $412 \mathrm{~nm}$ to $203.2 \mathrm{~nm}(P<0.001)$. Figure $3 \mathrm{~A}$ shows that increasing CSA concentration from 2 to $4 \mathrm{wt} \%$ increased the PDI from 0.231 to $0.282(P<0.001)$, while increasing Tween 80 concentration from 0.5 to $1 \mathrm{wt} \%$ resulted in an increase in PDI from 0.240 to 0.286 , but PDI dropped to 0.240 when Tween 80 concentration reached $2 \mathrm{wt} \%$. Similar results for the effect of Tween 80 on PDI were obtained in a previous study of the incorporation of flurbiprofen into lipid nanoparticles. ${ }^{32}$

The positive effect of increasing CSA ratio on PS enlargement may be due to the deposition of CSA on the surface of the solidified Compritol, as Compritol has a higher melting point $\left(65^{\circ} \mathrm{C}-77^{\circ} \mathrm{C}\right)$ and will start solidifying earlier than CSA (which has a melting point of $48^{\circ} \mathrm{C}-56^{\circ} \mathrm{C}$ ). Also, as the ratio of CSA increases the $\mathrm{EE} \%$ of MZA increases, as previously discussed, which also results in an increase in PS due to an increase in the amount of the drug entrapped in the NLMs. On the other hand, the effect of Tween 80 on PS reduction could be attributed to the larger amount of surfactant

B

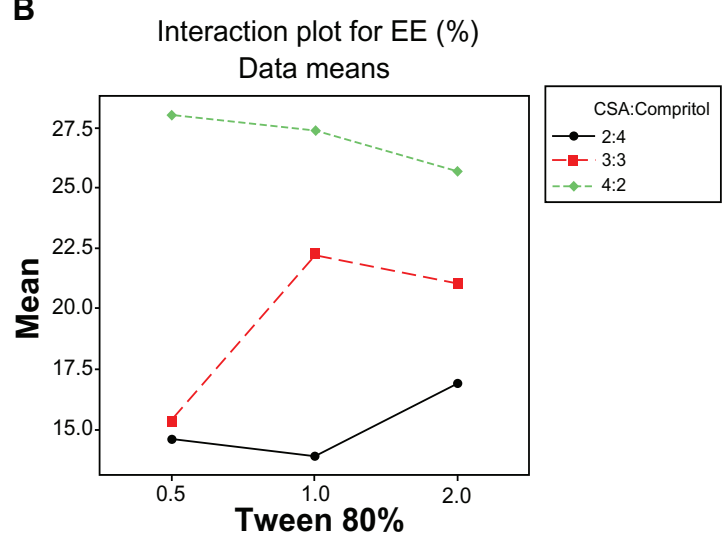

Figure I Main effect (A) and interaction plot (B) for EE\% of MZA in NLMs.

Abbreviations: CSA, cetostearyl alcohol; EE, entrapment efficiency; MZA, methazolamide; NLMs, nanostructured lipid matrices. 
Table 4 ANOVA statistical analysis for dependent variables (PDI and ZP)

\begin{tabular}{|c|c|c|c|c|c|c|c|}
\hline \multirow{2}{*}{$\begin{array}{l}\text { Source of } \\
\text { variation }\end{array}$} & \multirow[t]{2}{*}{ DF } & \multicolumn{3}{|l|}{ PDI } & \multicolumn{3}{|l|}{$\mathrm{ZP}(\mathrm{mV})$} \\
\hline & & $\begin{array}{l}\text { Sum of } \\
\text { squares }\end{array}$ & $\begin{array}{l}\text { Mean } \\
\text { square }\end{array}$ & $F$ value & $\begin{array}{l}\text { Sum of } \\
\text { squares }\end{array}$ & $\begin{array}{l}\text { Mean } \\
\text { square }\end{array}$ & $F$ value \\
\hline CSA:Compritol & 2 & 0.0117 & 0.0059 & $53.27^{\mathrm{s}}$ & 2.105 & 1.053 & 3.18 \\
\hline Tween 80 & 2 & 0.0128 & 0.0064 & $58.22^{\mathrm{s}}$ & 563.945 & 281.973 & $850.67^{s}$ \\
\hline $\begin{array}{l}\text { CSA:Compritol - } \\
\text { Tween } 80\end{array}$ & 4 & 0.0053 & 0.0013 & $12.03^{s}$ & 6.950 & I.738 & 5.24 \\
\hline Error & 17 & 0.0018 & 0.0001 & - & 5.635 & 0.331 & - \\
\hline Total & 26 & 0.0317 & - & - & 578.650 & - & - \\
\hline
\end{tabular}

Note: Significant at $P<0.001$.

Abbreviations: ANOVA, analysis of variance; CSA, cetostearyl alcohol; DF, degrees of freedom; PDI, polydispersity index; ZP, zeta potential.

available to cover the lipid surface, which lowers the interfacial tension and allows smaller particles to be formed. ${ }^{33,34}$

Data presented in Tables 3 and 4 indicate that there was a significant two-way interaction $(P<0.001)$ between lipid composition and Tween 80 concentration concerning PS and PDI. As the Tween 80 percentage increased from 0.5 to $2 \mathrm{wt} \%$, the effect of PS enlargement caused by increasing CSA ratio diminished until it disappeared at $2 \mathrm{wt} \%$ Tween 80 . This gave a similar mean PS regardless of the ratio of CSA (Figure 2B).

\section{Zeta potential response}

The results of Zeta potential (ZP) are displayed in Table 2. All MZA-NLM systems carried a positive charge due to the presence of stearylamine. The $\mathrm{ZP}$ values were higher than $30 \mathrm{mV}$, ranging from $41.5 \mathrm{mV}$ to $53.25 \mathrm{mV}$ which indicates that particle aggregation is less likely to occur due to electrostatic repulsion between particles with same electrical charge producing stable dispersions.

Table 4 shows that only Tween 80 concentration had a significant effect on MZA-loaded NLMs ZP $(P<0.001)$ while CSA:Compritol ratio had no significant effect. Figure 4A shows that increasing Tween 80 concentration

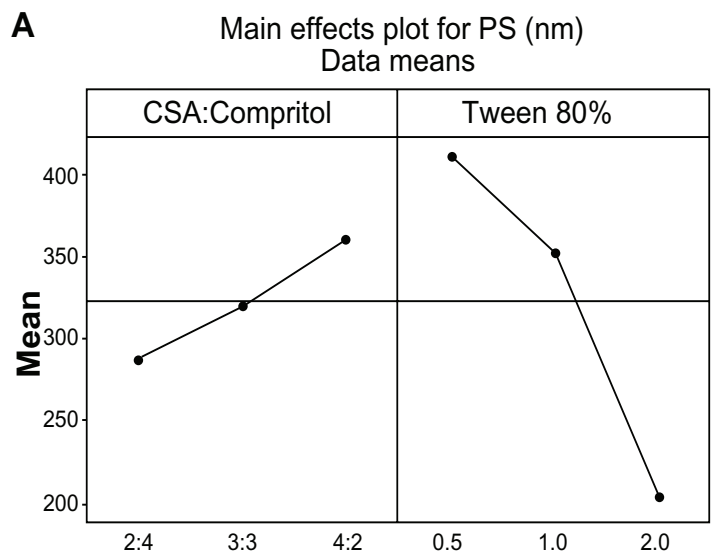

Figure 2 Main effect (A) and interaction plot (B) for PS of MZA-loaded NLMs. Abbreviations: CSA, cetostearyl alcohol; MZA, methazolamide; PS, particle size. from 0.5 to $2 \mathrm{wt} \%$ decreased the $\mathrm{ZP}$ from $52.90 \mathrm{mV}$ to $42.26 \mathrm{mV}(P<0.001)$. This is due to the nonionic character of Tween 80 reducing the positive charge expressed on the surface of nanoparticles ${ }^{35}$ From the results illustrated in Figure 4B and tabulated in Table 4, it is clear that there was no significant two-way interaction $(P<0.001)$ between lipid composition and Tween 80 concentration.

\section{Electron microscope examination}

Morphological examination of representative MZA-loaded NLM formulations (NLM-5, NLM-6, and NLM-9) was performed using TEM (see Figure 5). This revealed that all the prepared particles were spherical in shape without aggregation, with an increase in mean PS correlated with increasing CSA ratio (Figure 5A and B), and a decrease in mean PS correlated with increasing Tween 80 concentration (Figure 5C) as was previously discussed.

\section{In vitro release of MZA from NLMs}

Release studies were carried out on MZA-loaded NLM formulae NLM-5, NLM-6, and NLM-9, which gave the highest $\mathrm{EE} \%$ and suitable particle sizes ranging from

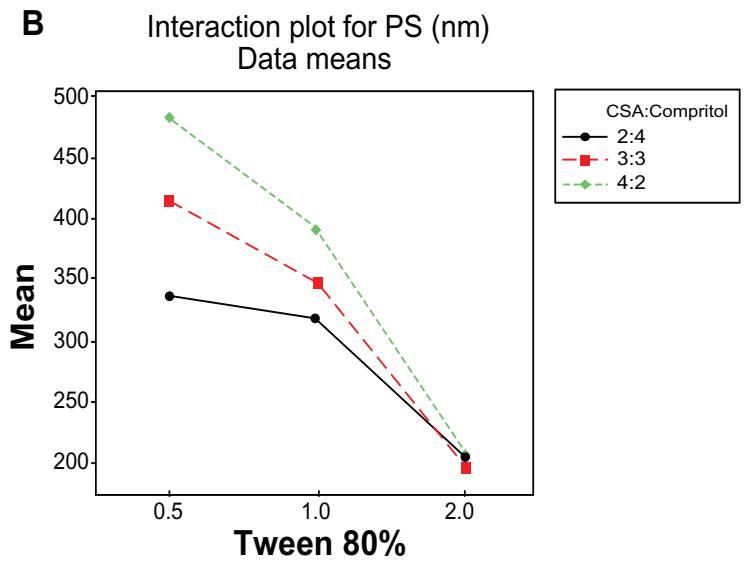


A

Main effects plot for PDI

Data means

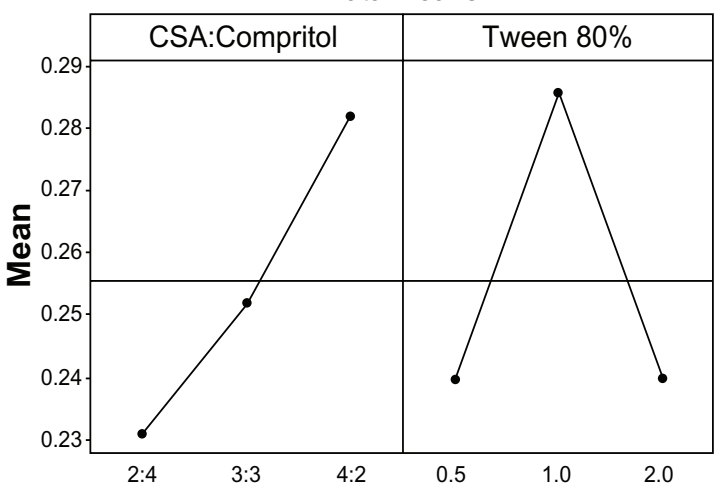

B
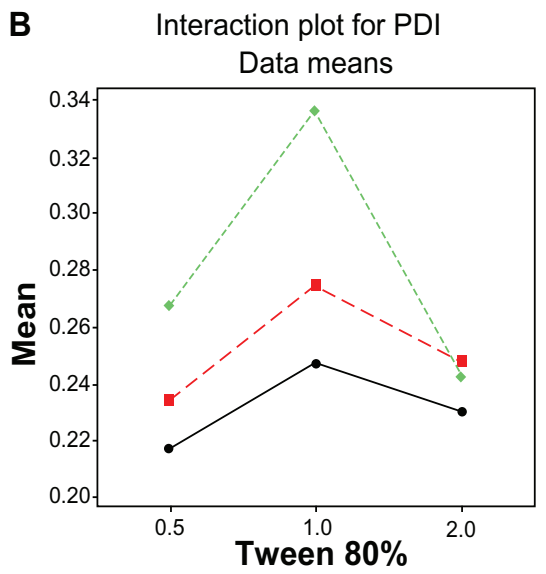

\begin{tabular}{|r|}
\hline CSA:Compritol \\
\hdashline$-2: 4$ \\
$-3: 3$ \\
$-4: 2$
\end{tabular}

Figure 3 Main effect (A) and interaction plot (B) for PDI of MZA-loaded NLMs.

Abbreviations: CSA, cetostearyl alcohol; MZA, methazolamide; PDI, polydispersity index.

$207.1 \mathrm{~nm}$ to $391.7 \mathrm{~nm}$. The results were compared with MZA-entrapped SLN formula SLN-1. The release profiles shown in Figure 6 revealed that entrapment of MZA into NLMs sustained and controlled the release of the drug over a prolonged period. The sustained effect was dependent on the lipid mixture ratio (3:3 or 4:2 CSA:Compritol $w t^{\%} \%$ ) and percentage of Tween 80 ( 1 or $2 \mathrm{wt} \%$ ). The release patterns can be arranged in the following prolonged order: NLM-6 > NLM-9 > NLM-5 > SLN-1.

The common feature in these profiles was an initial burst effect with approximately 30.68\%, 36.12\%, 39.27\%, and $43.31 \%$ of drug being released in the first hour for NLM-6, NLM-9, NLM-5, and SLN-1, respectively. This was followed by a slower exponential release of the remaining drug with approximately $75.37 \%, 84.88 \%, 90.03 \%$, and $97.85 \%$ of drug being released over the following 8 hours, respectively. It is clear that using a mixture of lipids could decrease the burst effect and sustain MZA release better than a single lipid alone, as this provided the fastest release. The initial burst effect could be attributed to the portion of the drug that was positioned on the outer shell of the NLMs, this is followed by the slower release of the remaining drug that was entrapped inside the core of the NLMs. The presence of the drug in the outer shell of the NLMs has been explained as a result of reduction in drug solubility in the aqueous phase during solidification of NLMs. This forces the drug to go to the lipid phase that has already been recrystallized and so is prevented from entering the lipid core, which means that it is concentrated on the surface of the NLMs. ${ }^{3,36}$

By further inspection of the release profiles it was concluded that increasing the CSA content from $3 \mathrm{wt} \%$ (NLM-5) to 4 wt\% (NLM-6, NLM-9) reduced MZA release. Formula NLM-6 showed the slowest release pattern, reaching about $75 \%$ of MZA released over 8 hours. This may be attributed

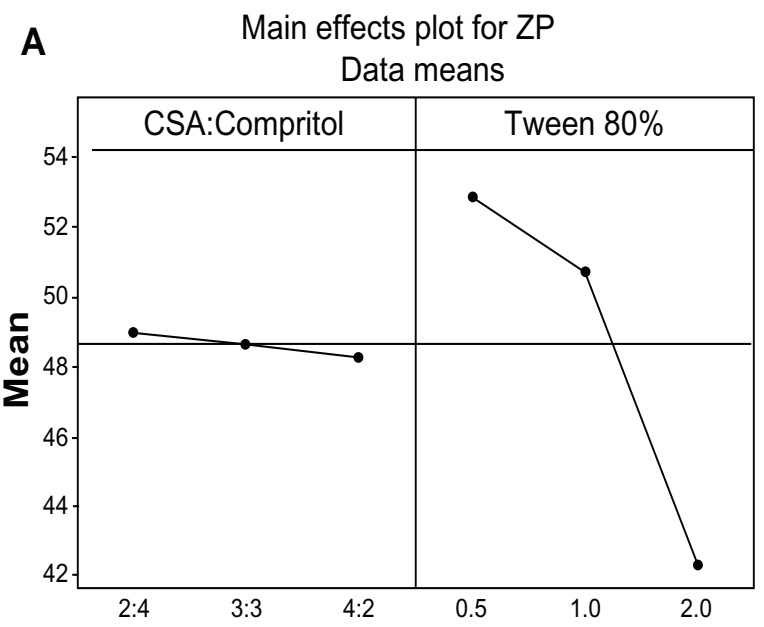

\section{B Interaction plot for ZP}

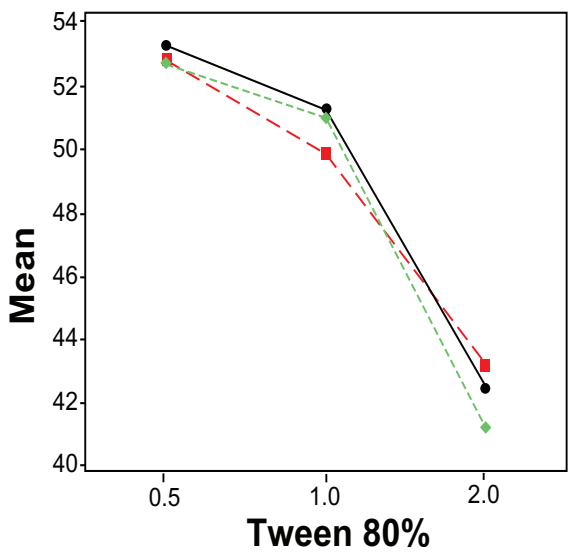

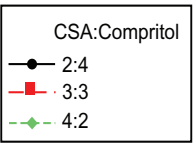

Figure 4 Main effect (A) and interaction plot (B) for ZP of MZA-loaded NLMs.

Abbreviations: CSA, cetostearyl alcohol; MZA, methazolamide; NLMs, nanostructured lipid matrices, ZP, zeta potential. 
A

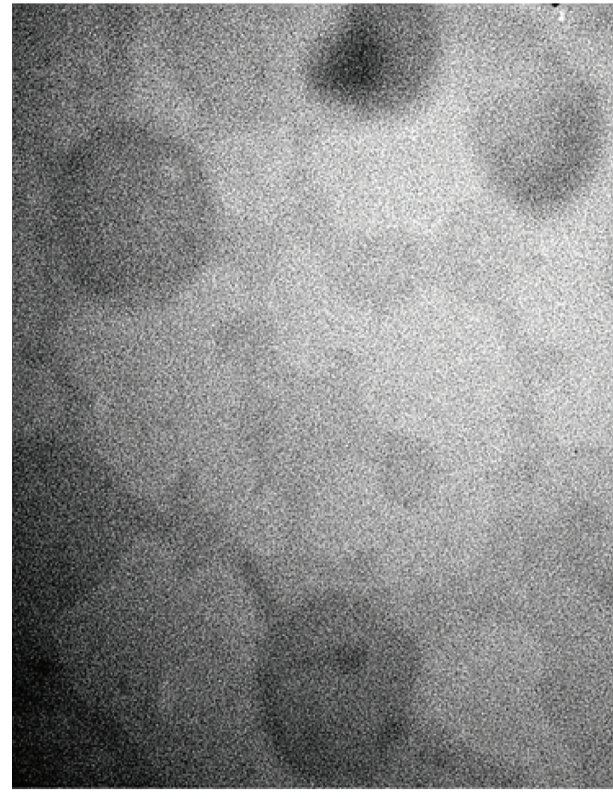

$500 \mathrm{~nm}$ TEM Mag $=60000 x$
B

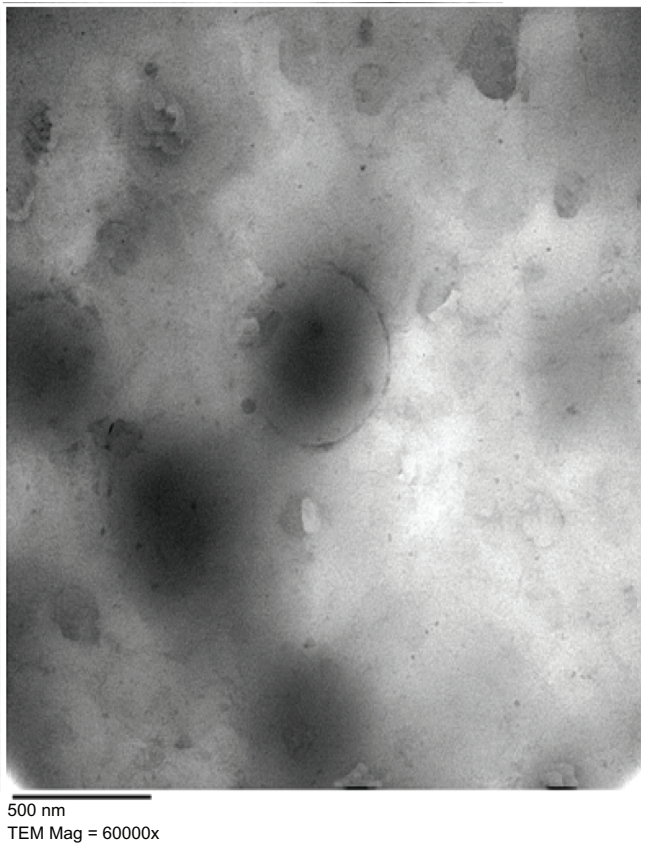

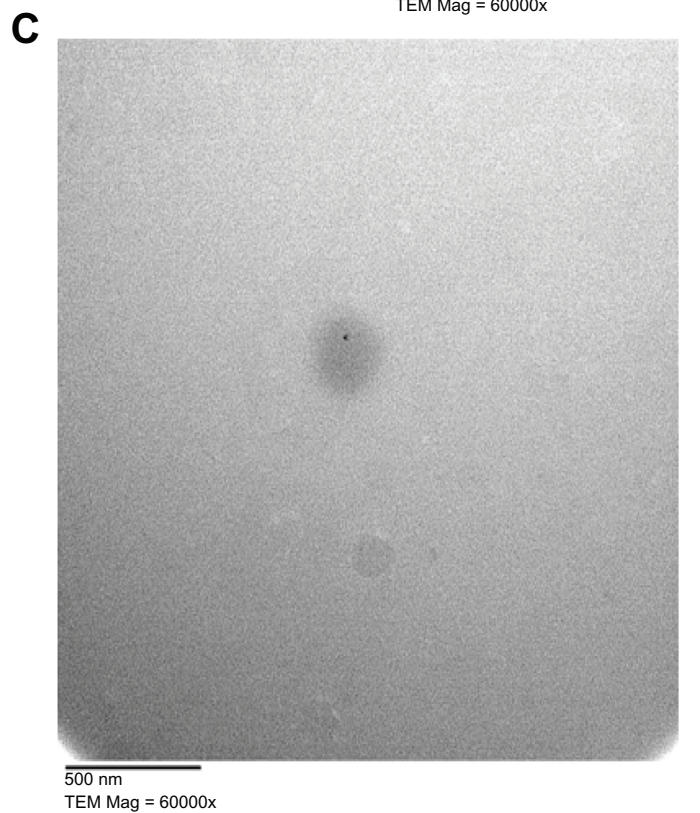

Figure 5 Electron micrographs of MZA-loaded NLMs. (A) NLM-5, (B) NLM-6, (C) NLM-9.

Abbreviations: MZA, methazolamide; NLMs, nanostructured lipid matrices; TEM, transmission electron microscope.

to the higher EE\% of MZA and larger PS in formula NLM-6, which meant that a smaller surface area was exposed to the release medium. From the results of formulations containing $4 \mathrm{wt} \% \mathrm{CSA}$, we can conclude that increasing the Tween 80 concentration from $1 \mathrm{wt} \%$ (NLM-6) to $2 \mathrm{wt} \%$ (NLM-9) increased the rate of drug release due to Tween 80 's action as a surfactant, which enhanced drug solubility in the release medium in addition to lowering the PS that itself led to an increase in the surface area of the particles.

\section{Differential scanning calorimetry}

Figure 7 shows differential scanning calorimetry (DSC) thermograms for MZA, the physical mixture composed of Compritol, CSA, MZA, and stearylamine, unloaded NLMs, and MZA-loaded NLM formula NLM-9. Formula NLM-9 was chosen for DSC study as it showed high EE\% and very small PS. MZA showed a sharp, narrow peak at $205.67^{\circ} \mathrm{C}$ with enthalpy of $13.18 \mathrm{~J} / \mathrm{g}$ representing its melting point and confirming its crystalline nature. While the physical mixture showed a sharp narrow peak at $48.94^{\circ} \mathrm{C}$ with enthalpy of 


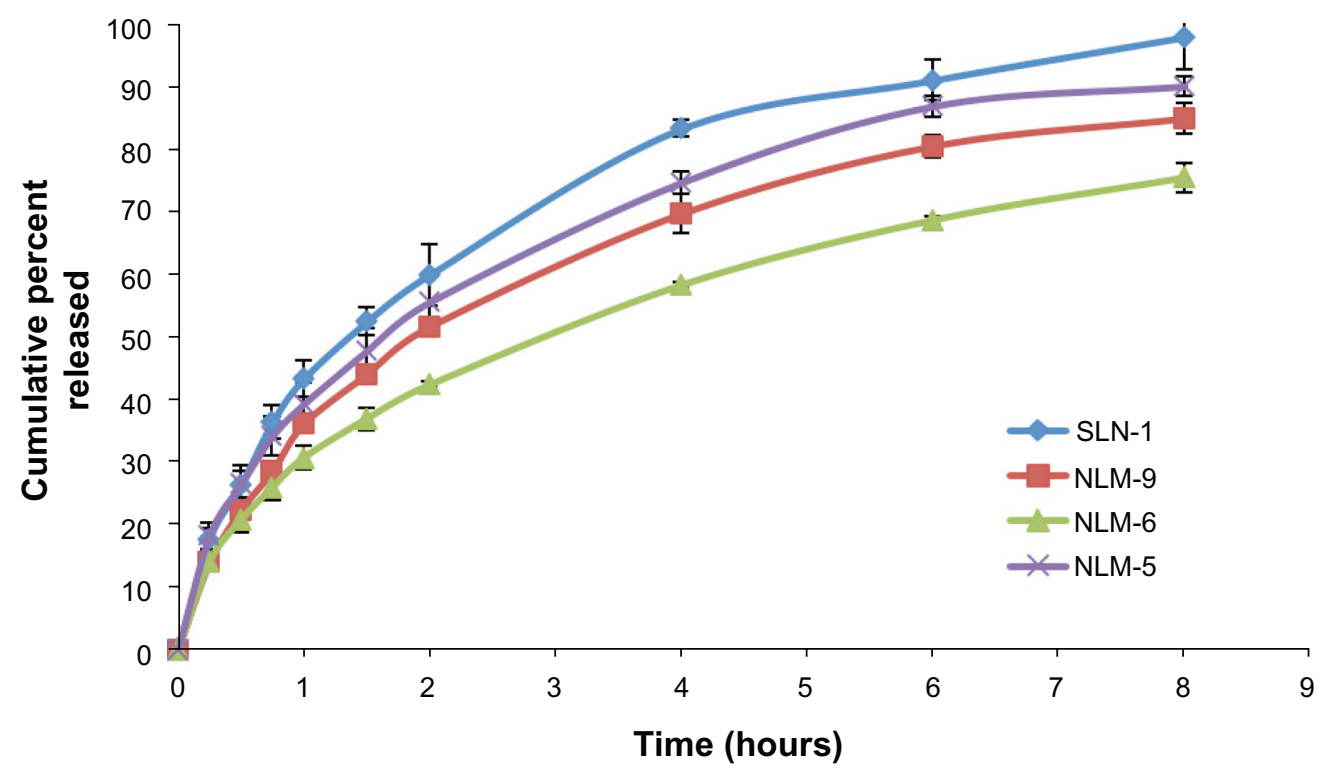

Figure 6 Release profiles for MZA-loaded NLM formulations NLM-5, NLM-6, and NLM-9 compared to SLN-I.

Note: Each value represents the mean \pm SD $(n=3)$.

Abbreviations: MZA, methazolamide; NLM, nanostructured lipid matrices; SD, standard deviation; SLN, solid lipid nanoparticles.

$14.46 \mathrm{~J} / \mathrm{g}$, this is the average of melting points of Compritol and CSA, indicating that both Compritol and CSA are found in a crystalline state. It also showed another very small peak at $201.10^{\circ} \mathrm{C}$ (shown by the arrow in Figure 7 ) with enthalpy of $0.09 \mathrm{~J} / \mathrm{g}$ representing the MZA peak. The small magnitude of this peak may be due to the small amount of MZA found in the physical mixture. Both unloaded and loaded NLM-9 formulae gave rise to a broad very small peak at $51.2^{\circ} \mathrm{C}$ with enthalpy of $3.36 \mathrm{~J} / \mathrm{g}$ and $52.95^{\circ} \mathrm{C}$ with enthalpy
$3.10 \mathrm{~J} / \mathrm{g}$, respectively. The broadening of the peak accompanied with a decrease in the enthalpy and height of the melting peak indicates a decrease in the crystallinity of the lipids, which shows that incorporating lipids in NLMs led to major defects in the crystal lattice of the lipids, giving rise to more space to successfully entrap the drug. The onset of the peak of MZA-loaded NLM formula NLM-9 was at $47.67^{\circ} \mathrm{C}$, which confirms the solid nature of lipids when exposed to body temperature (as this is above $40^{\circ} \mathrm{C}$,

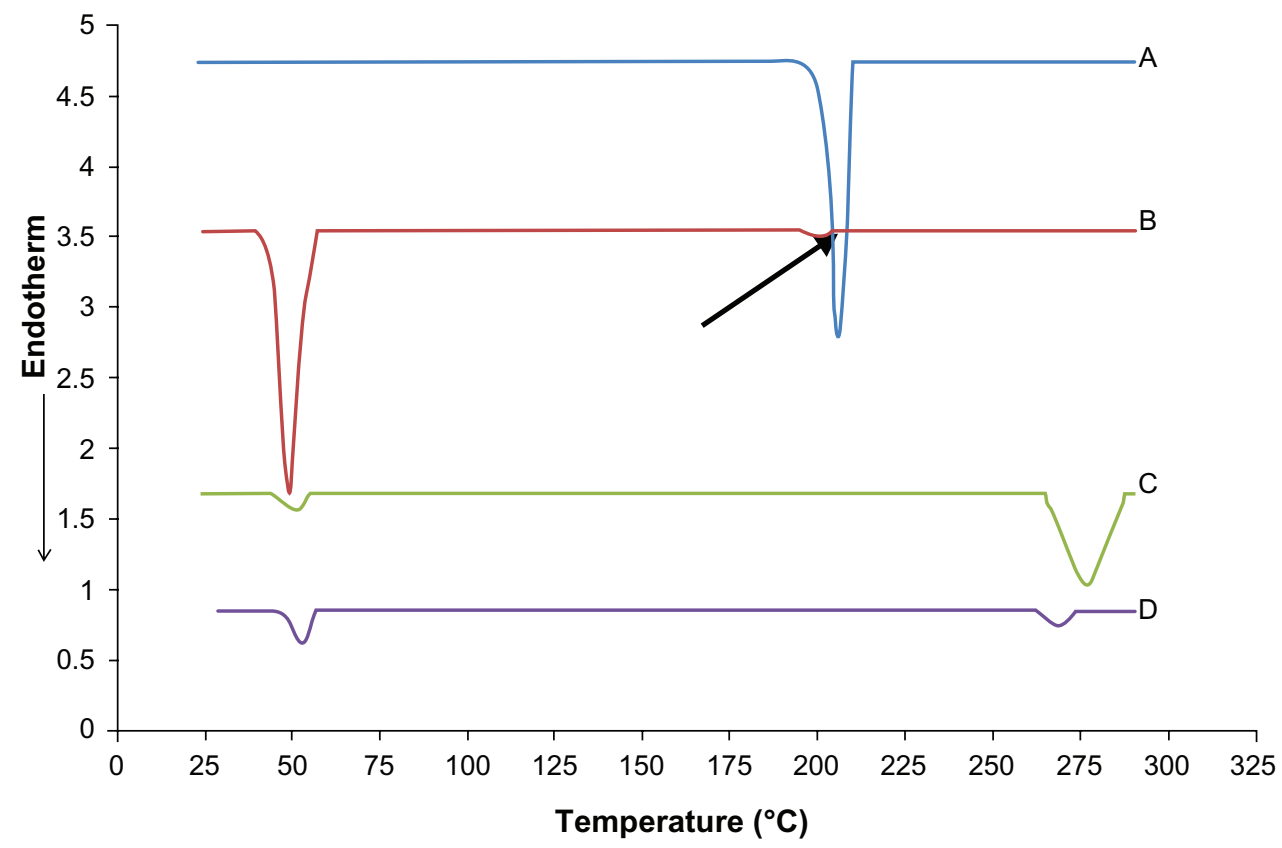

Figure 7 DSC thermograms for (A) pure MZA, (B) physical mixture, (C) unloaded NLM-9, and (D) MZA-loaded formula NLM-9.

Note: The arrow indicates the MZA peak at $201.10^{\circ} \mathrm{C}$ in the physical mixture.

Abbreviations: DSC, differential scanning calorimetry; MZA, methazolamide; NLM, nanostructured lipid matrix. 
so avoiding the presence of the nanoemulsion in which the advantages of NLMs will be lost). The disappearance of the MZA melting peak in the DSC thermogram of NLM-9 indicates that the drug is not in a crystalline state (ie, is amorphous) or molecularly dispersed in the lipid matrix. Similar results have been observed by many authors. ${ }^{35,37-39}$

\section{X-ray diffraction}

$\mathrm{X}$-ray diffraction was carried out to evaluate the crystallinity of MZA-loaded NLM formula NLM-9 and compare it to that of pure MZA, Compritol, and CSA (see Figure 8). The MZA $\mathrm{X}$-ray diffractogram shows several sharp, narrow peaks between $10^{\circ}$ and $40^{\circ}(2 \theta)$ with maximum peak intensity at $2 \theta=13.87^{\circ}(d=6.37 \AA)$, indicating its crystalline nature. The X-ray diffractogram of CSA showed four major sharp peaks with a maximum peak at $2 \theta=21.29^{\circ}(d=4.16 \AA)$, while Compritol showed only two sharp peaks with the maximum at $2 \theta=21.18^{\circ}(d=4.189 \AA)$. In the case of formula NLM-9 there was only one major peak at $2 \theta=21.15^{\circ}$ $(d=4.19 \AA)$, which probably represented an overlapped peak of both CSA and Compritol. Also, it is clear that the peaks of MZA disappeared from the diffraction pattern of NLM-9, indicating its amorphous state and confirming the results of DSC analysis. It is known that the intensity of peaks is related to the crystallinity of the sample, with a higher peak intensity indicating that the material is more crystalline. Given that the peak intensity of NLM-9 showed a sharp decrease when compared to that of Compritol or CSA, this indicates a marked decrease in the crystallinity of NLMs and confirms previous results from the DSC analysis.

\section{Effect of aging}

To assess the effect of aging on the prepared NLMs, mean PS was measured following one month of refrigeration; the results of this are presented in Figure 9. Student's $t$-test analysis demonstrated that formulae NLM-1 and NLM-3 containing $0.5 \mathrm{wt} \%$ Tween 80 and formulae NLM-4 and NLM-5 containing $1 \mathrm{wt} \%$ Tween 80 showed significant change in mean PS $(P<0.01)$. However, all formulae were stable at $2 \mathrm{wt} \%$ Tween 80 , with no significant change in mean PS. This indicates that a higher concentration of Tween 80 leads to very high stability. As a general conclusion, NLMs showed very good stability after 1 month, with the mean PS of all formulae remaining below $500 \mathrm{~nm}$ (including those that showed a significant increase in PS). This may be attributed to the high positive charge induced by the presence of stearylamine, which would be expected to cause repulsion between particles, so avoiding their aggregation and coalescence, in addition to the stabilizing effect of Tween 80 .

\section{In vivo study on MZA-loaded NLMs}

MZA-loaded NLM formulae NLM-6 and NLM-9 were selected for the in vivo studies as they showed higher EE\% and prolonged drug release patterns. Figure 10 shows the reduction in the IOP of selected NLM formulations compared to that of MZA solution. It can been seen that the MZA solution caused the greatest reduction in the IOP effect after 3 hours, when a value of $-4.85 \mathrm{mmHg}$ was recorded, and the reduction lasted for a total of 5 hours. On the other hand, the IOP-lowering effect of MZA-loaded NLMs reached its peak after 3 hours, when values of -6.4 (NLM-6) and $-8.3 \mathrm{mmHg}$

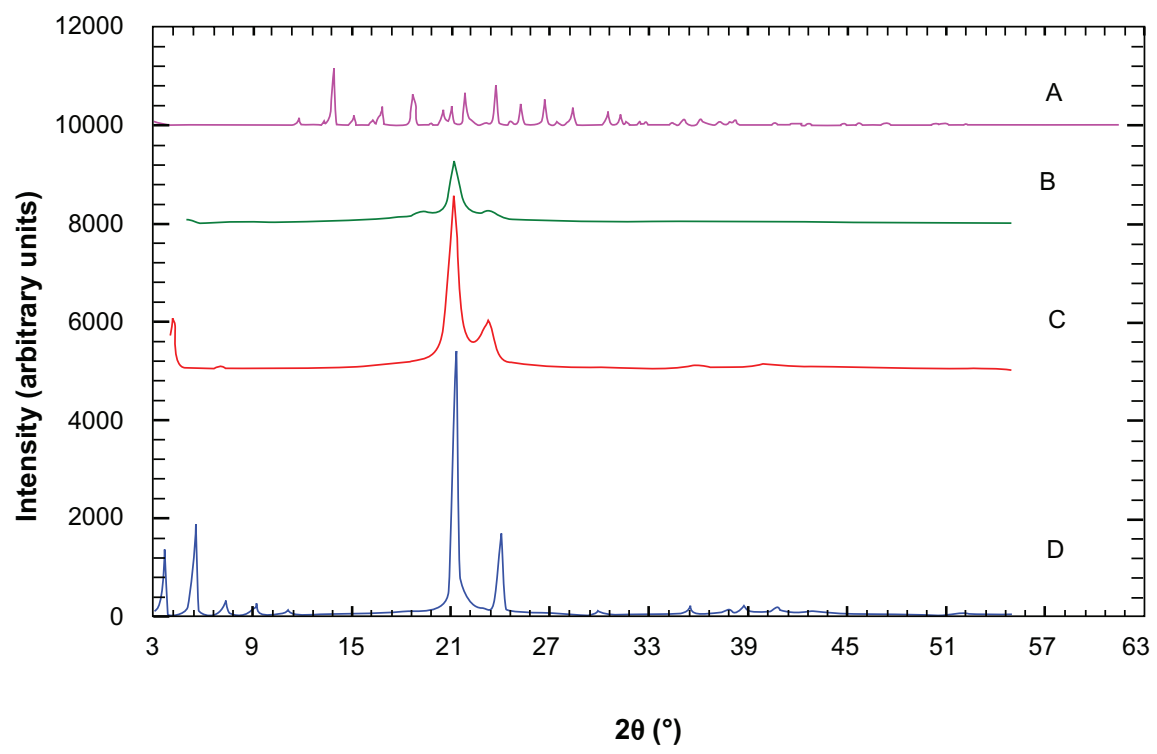

Figure 8 X-ray diffraction patterns for (A) MZA, (B) MZA-loaded NLM-9, (C) Compritol, and (D) CSA Abbreviations: CSA, cetostearyl alcohol; MZA, methazolamide. 


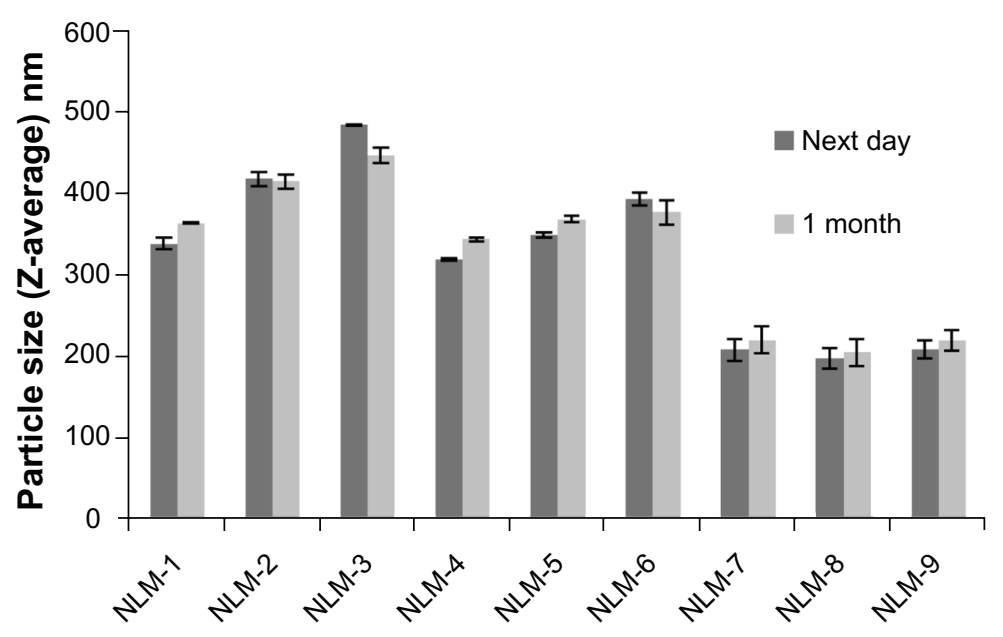

Formulation code

Figure 9 Change in mean PS of MZA-loaded NLMs after refrigeration for I month at $4^{\circ} \mathrm{C}$. Abbreviations: MZA, methazolamide; NLM, nanostructured lipid matrix.

(NLM-9) were recorded; reductions lasted for 10 hours and about 12 hours, respectively, as shown in Table 5. Entrapping MZA in NLMs significantly enhanced its IOP-lowering activity and increased its duration of action compared to the MZA solution $(P<0.05)$. It is likely that the increase in IOP-lowering activity is due to improved ocular penetration of MZA entrapped in NLMs. This may be attributed to their lipophilic nature facilitating the penetration of the highly hydrophobic epidermis of the cornea. ${ }^{6}$ Furthermore, the increased duration of action might be due to adherence of NLMs to ocular membranes, preventing tear wash out owing to their small size, cationic charge, and particulate nature. ${ }^{7}$

The area under the curve (AUC) was calculated as shown in Table 5. It can be seen that formula NLM-9 provided the highest pharmacological response, followed by formula
NLM-6; both were significantly $(P<0.05)$ higher than MZA solution. The higher AUC for formula NLM-9 (nearly double that of formula NLM-6) may be due to the higher concentration of Tween 80 ( $2 \mathrm{wt} \%)$, as Tween 80 is a polyoxyethylated nonionic surfactant that acts as a penetration enhancer, removing the mucus layer and breaking junctional complexes, ${ }^{19}$ so improving MZA ocular permeability. In addition, Tween 80 is a P-glycoprotein efflux pump inhibitor, ${ }^{40} \mathrm{P}$-glycoprotein efflux pump is present in the cornea, ${ }^{41}$ so Tween 80 's reduction of the efflux of MZA will increase its duration of action.

Gross examination of the rabbit eyes during this study did not uncover any signs of abnormal lacrimation or increased blinking upon instillation of the prepared NLM formulations.

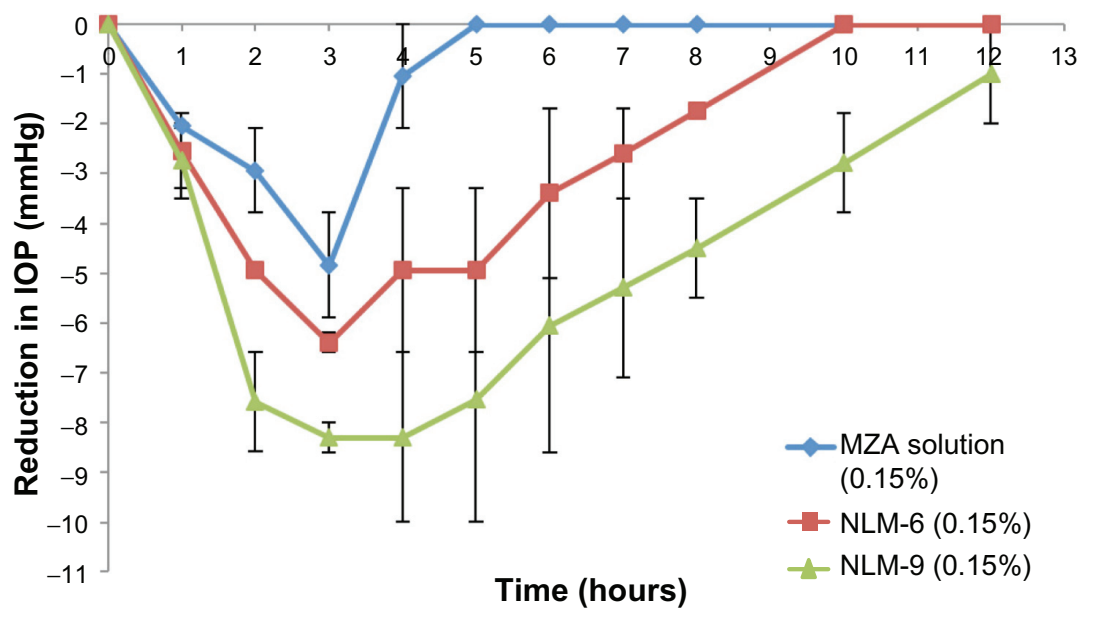

Figure 10 Reduction in IOP after administration of topical MZA-loaded NLM-6 and NLM-9 compared to MZA solution. Abbreviations: IOP, intraocular pressure; MZA, methazolamide; NLM, nanostructured lipid matrix. 
Table 5 Analysis of in vivo results for MZA-entrapped formulae NLM-6 and NLM-9 compared to MZA solution

\begin{tabular}{lllr}
\hline Formula & $\begin{array}{l}\text { Maximum decrease } \\
\text { in IOP }(\mathbf{m m H g})\end{array}$ & $\begin{array}{l}\mathbf{T}_{\text {max }} \\
\text { (hours) }\end{array}$ & \multicolumn{1}{l}{ AUC } \\
\hline $0.15 \%$ MZA & $-4.85 \pm 1.05$ & 3 & $10.9 \pm 1.83$ \\
solution & & & $32.425 \pm 7.88^{\circ}$ \\
NLM-6 & $-6.4 \pm 0.19$ & 3 & $64.2 \pm 5.25^{\circ}$ \\
NLM-9 & $-8.3 \pm 0.29$ & 3 & \\
\hline
\end{tabular}

Note: sSignificant difference from MZA solution $(P<0.05)$.

Abbreviations: AUC, area under the curve; IOP, intraocular pressure; MZA, methazolamide; NLM, nanostructured lipid matrix.

\section{Conclusion}

Cationic MZA-loaded NLMs were successfully prepared using heterolipids, and were characterized by mean PS below $500 \mathrm{~nm}$ for all formulations using Tween 80 as an emulsifier. The NLMs remained stable for at least 1 month when stored at $4{ }^{\circ} \mathrm{C}$. Increasing $\mathrm{CSA}$ concentration was accompanied by an increase in $\mathrm{MZA} E \mathrm{E} \%$, which reached its highest value at $4 \mathrm{wt} \%$. In contrast, various levels of Tween $80 \mathrm{did}$ not affect EE\%, but PS did drop as Tween 80 concentration increased. In vitro release studies showed that both the CSA:Compritol ratio and Tween 80 concentration affected the release rate of MZA from NLMs. Release could be sustained for about 8 hours. NLMs provided higher $\mathrm{EE} \%$ and slower MZA release rate compared to SLNs, indicating that they were superior drug carriers. DSC studies confirmed the solid nature of NLMs at room temperature. X-ray diffraction pattern analysis showed a marked decrease in NLM crystallinity. In vivo results showed that NLMs were successful in ocular delivery of MZA, with no visual irritation and a marked decrease in IOP providing a higher pharmacological response and more sustained effect than MZA solution. This suggests that NLMs are suitable as a topical ocular delivery carrier for MZA in treatment of glaucoma.

\section{Disclosure}

The authors report no conflicts of interest in this work.

\section{References}

1. Law SL, Huang KJ, Chiang CH. Acyclovir-containing liposomes for potential ocular delivery. Corneal penetration and absorption. J Control Release. 2000;63(1-2):135-140.

2. Meisner D, Mezei M. Liposome ocular delivery systems. Adv Drug Deliv Rev. 1981;16(1):75-93.

3. Müller RH, Mäder K, Gohla S. Solid lipid nanoparticles (SLN) for controlled drug delivery - a review of the state of the art. Eur J Pharm Biopharm. 2000;50(1):161-177.

4. Jores K, Mehnert W, Drechsler M, Bunjes H, Johann C, Mäder K. Investigations on the structure of solid lipid nanoparticles (SLN) and oil-loaded solid lipid nanoparticles by photon correlation spectroscopy, field-flow fractionation and transmission electron microscopy. J Control Release. 2004;95(2):217-227.
5. Mehnert W, Mäder K. Solid lipid nanoparticles: production, characterization and applications. Adv Drug Deliv Rev. 2001;47(2-3): 165-196.

6. Attama AA, Reichl S, Müller-Goymann CC. Diclofenac sodium delivery to the eye: in vitro evaluation of novel solid lipid nanoparticle formulation using human cornea construct. Int J Pharm. 2008;355(1-2):307-313.

7. Müller-Goymann CC. Physicochemical characterization of colloidal drug delivery systems such as reverse micelles, vesicles, liquid crystals and nanoparticles for topical administration. Eur J Pharm Biopharm. 2004;58(2):343-356.

8. Pardeike J, Hommoss A, Müller RH. Lipid nanoparticles (SLN, NLC) in cosmetic and pharmaceutical dermal products. Int J Pharm. 2009;366(1-2):170-184.

9. Jenning V, Thünemann AF, Gohla SH. Characterisation of a novel solid lipid nanoparticle carrier system based on binary mixtures of liquid and solid lipids. Int J Pharm. 2000;199(2):167-177.

10. Attama AA, Schicke BC, Müller-Goymann CC. Further characterization of theobroma oil-beeswax admixtures as lipid matrices for improved drug delivery systems. Eur J Pharm Biopharm. 2006;64(3):294-306.

11. Wissing SA, Kayser O, Müller RH. Solid lipid nanoparticles for parenteral drug delivery. Adv Drug Deliv Rev. 2004;56(9):1257-1272.

12. Friedlaender MH, Takruri H, inventor; Riolan Tehcnologies, Inc, assignee. Compositions, methods, and kits for treating dry eye. United States Patent 20070259021. November 8, 2007.

13. Maren TH, Haywood JR, Chapman SK, Zimmerman TJ. The pharmacology of methazolamide in relation to the treatment of glaucoma. Invest Ophthalmol Vis Sci. 1977;16(8):730-742.

14. Edelhauser HF, Maren TH. Permeability of human cornea and sclera to sulfonamide carbonic anhydrase inhibitors. Arch Ophthalmol. 1988;106(8):1110-1115.

15. Fridriksdóttir H, Loftsson T, Stefánsson E. Formulation and testing of methazolamide cyclodextrin eye drop solutions. J Control Release. 1997;44(1):95-99.

16. Chen R, Qian Y, Li R, et al. Methazolamide calcium phosphate nanoparticles in an ocular delivery system. Yakugaku Zasshi. 2010;130(3): 419-424.

17. Qian Y, Wang F, Li R, Zhang Q, Xu Q. Preparation and evaluation of in situ gelling ophthalmic drug delivery system for methazolamide. Drug Dev Ind Pharm. 2010;36(11):1340-1347.

18. Li R, Jiang S, Liu D, et al. A potential new therapeutic system for glaucoma: solid lipid nanoparticles containing methazolamide. J Microencapsul. 2011;28(2):134-141.

19. Kaur IP, Garg A, Singla AK, Aggarwal D. Vesicular systems in ocular drug delivery: an overview. Int J Pharm. 2004;269(1):1-14.

20. Hou D, Xie C, Huang K, Zhu C. The production and characteristics of solid lipid nanoparticles (SLNs). Biomaterials. 2003;24(10):1781-1785.

21. Nasr M, Mansour S, Mortada ND, El Shamy AA. Lipospheres as carriers for topical delivery of aceclofenac: preparation, characterization and in vivo evaluation. AAPS Pharm Sci Tech. 2008;9(1):154-162.

22. Hathout RM, Mansour S, Mortada ND, Guinedi AS. Liposomes as an ocular delivery system for acetazolamide: in vitro and in vivo studies. AAPS Pharm Sci Tech. 2007;8(1):1.

23. Winum JY, Casini A, Mincione F, et al. Carbonic anhydrase inhibitors: $\mathrm{N}$-(p-sulfamoylphenyl)-alpha-D-glycopyranosylamines as topically acting antiglaucoma agents in hypertensive rabbits. Bioorg Med Chem Lett. 2004;14(1):225-229.

24. Monem AS, Ali FM, Ismail MW. Prolonged effect of liposomes encapsulating pilocarpine $\mathrm{HCl}$ in normal and glaucomatous rabbits. Int J Pharm. 2000;198(1):29-38.

25. Hazleton LW. Relation of surface-active properties of irritation of the rabbit eye. Proc Sci Sect T GA. 1952:17-18.

26. Klang S, Frucht-Pery J, Hoffman A, Benita S. Physicochemical characterization and acute toxicity evaluation of a positively-charged submicron emulsion vehicle. J Pharm Pharmacol. 1994;46(12):986-993.

27. Attama AA, Schicke BC, Paepenmüller T, Müller-Goymann CC. Solid lipid nanodispersions containing mixed lipid core and a polar heterolipid: characterization. Eur J Pharm Biopharm. 2007;67(1):48-57. 
28. Sanna V, Caria G, Mariani A. Effect of lipid nanoparticles containing fatty alcohols having different chain length on the ex vivo skin permeability of econazole nitrate. Powder Technology. 2010;201(1):32-36.

29. Varshosaz J, Tabbakhian M, Mohammadi MY. Formulation and optimization of solid lipid nanoparticles of buspirone $\mathrm{HCl}$ for enhancement of its oral bioavailability. J Liposome Res. 2010;20(4):286-296.

30. Varshosaz J, Minayian M, Moazen E. Enhancement of oral bioavailability of pentoxifylline by solid lipid nanoparticles. J Liposome Res. 2010;20(2):115-123.

31. Zimmer A, Kreuter J. Microspheres and nanoparticles used in ocular delivery systems. Adv Drug Deliv Rev. 1995;16:61-73.

32. Gonzalez-Mira E, Egea MA, Garcia ML, Souto EB. Design and ocular tolerance of flurbiprofen loaded ultrasound-engineered NLC. Colloids Surf B Biointerfaces. 2010;81(2):412-421.

33. Schubert MA, Müller-Goymann CC. Characterisation of surfacemodified solid lipid nanoparticles (SLN): influence of lecithin and nonionic emulsifier. Eur J Pharm Biopharm. 2005;61(1-2):77-86.

34. Attama AA, Müller-Goymann CC. Investigation of surface-modified solid lipid nanocontainers formulated with a heterolipid-templated homolipid. Int J Pharm. 2007;334(1-2):179-189.

35. Kheradmandnia S, Vasheghani-Farahani E, Nosrati M, Atyabi F. Preparation and characterization of ketoprofen-loaded solid lipid nanoparticles made from beeswax and carnauba wax. Nanomedicine. 2010;6(6):753-759.
36. zur Mühlen A, Schwarz C, Mehnert W. Solid lipid nanoparticles (SLN) for controlled drug delivery - drug release and release mechanism. Eur J Pharm Biopharm. 1998;45(2):149-155.

37. Venkateswarlu V, Manjunath K. Preparation, characterization and in vitro release kinetics of clozapine solid lipid nanoparticles. J Control Release. 2004;95(3):627-638.

38. Lv Q, Yu A, Xi Y, et al. Development and evaluation of penciclovirloaded solid lipid nanoparticles for topical delivery. Int J Pharm. 2009;372(1-2):191-198.

39. Cavalli R, Peira E, Caputo O, Gasco MR. Solid lipid nanoparticles as carriers of hydrocortisone and progesterone complexes with beta-cyclodextrins. Int J Pharm. 1999;182(1):59-69.

40. Jiao J. Polyoxyethylated nonionic surfactants and their applications in topical ocular drug delivery. Adv Drug Deliv Rev. 2008;60(15): $1663-1673$

41. Katragadda S, Talluri RS, Mitra AK. Modulation of P-glycoproteinmediated efflux by prodrug derivatization: an approach involving peptide transporter-mediated influx across rabbit cornea. $J$ Ocul Pharmacol Ther. 2006;22(2):110-120.
International Journal of Nanomedicine

\section{Publish your work in this journal}

The International Journal of Nanomedicine is an international, peerreviewed journal focusing on the application of nanotechnology in diagnostics, therapeutics, and drug delivery systems throughout the biomedical field. This journal is indexed on PubMed Central, MedLine, CAS, SciSearch $\AA$, Current Contents ${ }^{\circledR} /$ Clinical Medicine,

\section{Dovepress}

Journal Citation Reports/Science Edition, EMBase, Scopus and the Elsevier Bibliographic databases. The manuscript management system is completely online and includes a very quick and fair peer-review system, which is all easy to use. Visit http://www.dovepress.com/ testimonials.php to read real quotes from published authors. 